\title{
O Plano Municipal de Educação e suas repercussões na escola pública
}

The Municipal Plan of Education and its repercussions in the public school

Alex Vieira da Silva Doutorando em Educação e Professor do Centro de Educação da Universidade Federal de Alagoas Campus A. C. Simões, Maceió/Alagoas. Brasil. alexpedufal@gmail.com

Inalda Maria dos Santos Doutora em Educação. Professora do Centro de Educação e do Programa de Pós-graduação da Universidade Federal de Alagoas - Campus A. C. Simões, Maceió/Alagoas. Brasil. inaldasantos@uol.com.br

Resumo: $\mathrm{O}$ texto tem como objetivo apresentar as modificações na organização e na gestão da escola através da implementação do PME no "chão" da escola pública. A pesquisa foi realizada por meio de uma abordagem qualitativa. O tipo de entrevista aplicada foi a semiestruturada e a estratégia metodológica para o tratamento dos dados, a análise de conteúdo. Os sujeitos da pesquisa foram sete gestores escolares de escolas públicas dos municípios de Recife e de Olinda. Como resultados, foi possível perceber que as proposições evidenciadas possibilitam refletir que, diretamente, os Planos de Recife e de Olinda não causaram modificações no modo de organização na gestão da escola.

Palavras-chave: Plano Municipal de Educação. Gestão Escolar. Política Educacional.

Abstract: The text aims to present the changes in the organization and management of the school through the implementation of the SME in the "ground" of the public school. The research was carried out through a qualitative approach. The type of interview applied was the semi-structured and the methodological strategy for data processing, content analysis. The research subjects were seven public school administrators from the municipalities of Recife and Olinda. As results, it was possible to perceive that the evidenced propositions allow to reflect that, directly, the Plans of Recife and Olinda did not cause modifications in the way of organization in the management of the school.

Key words: Municipal Plan of Education. School management. Educational politics. 


\section{Introdução}

A discussão em torno do planejamento para a educação brasileira iniciou-se nos anos de 1930 com o movimento denominado de "Movimento dos Pioneiros da Escola Nova" (HORTA, 1982). Os Pioneiros, preocupados com a educação do país reivindicavam a elaboração de um plano para solucionar os problemas existentes na educação. Porém, este debate se estendeu ao longo dos anos apresentando perspectivas e ideários diferentes em relação ao planejamento.

Para Saviani (1999), nesse percurso histórico do planejamento, visando o Plano Nacional de Educação (PNE), tem-se inicialmente a ideia de plano de educação como um instrumento vinculado à racionalidade científica (MANIFESTO DOS PIONEIROS, 1932); depois, a ideia de plano como instrumento de controle ideológico (Estado Novo); o plano de educação como a ação do Estado a serviço do desenvolvimento econômico social do país e para a distribuição de recursos (1946-1964); e no período do regime militar os planos têm caráter tecnocrático sem a participação da sociedade no processo de elaboração.

Lembramos que com a Constituição Federal de 1988 (CF/1988) o planejamento da educação voltou a ser enfatizado. No seu texto está registrada a necessidade de criação do Plano Nacional de Educação, tendo a participação da sociedade civil na formulação das políticas públicas, uma vez que "passou a representar a pluralidade das vozes articuladas por meio das entidades da sociedade civil organizada. É o sujeito no coletivo, como ator social da cidadania" (BORDIGNON, 2011, p. 17).

A concepção de planejamento presente na CF/1988 consiste, segundo Sanches (1996), em um planejamento democrático-participativo, uma vez que a Carta de 1988 possibilitou um processo mais aberto de elaboração das leis orçamentárias, das políticas públicas, o que se diferencia dos períodos de 1964 a 1988. Para o autor, a nova Constituição ampliou "o âmbito de atuação do Legislativo nos processos de formulação e implementação de políticas públicas, e, por consequência, a intervenção das instituições da sociedade” (SANCHES, 1996, p. 1).

O Plano Nacional de Educação corresponde ao planejamento das metas que abrangem todos os aspectos relativos à organização da educação nacional. Este mecanismo marcou avanços significativos na sociedade brasileira, pois buscou unificar as políticas educacionais, uma vez que apresentou um panorama geral da educação nacional possibilitando um avanço no modo de pensar as políticas para a educação.

Nesse sentido, o PNE visa contribuir na implantação de políticas públicas educacionais que tenham como objetivo a construção de uma sociedade voltada para o desenvolvimento de uma educação capaz de transformar os sujeitos em indivíduos que sejam conscientes de sua 
participação no processo de tomada de decisões construindo uma sociedade justa, igualitária e referenciada socialmente.

No âmbito do planejamento educacional, os planos municipais de educação surgem como instrumentos para que os municípios possam desenvolver suas políticas para a educação, por meio das metas e das estratégias definidas no documento, elaboradas coletivamente com diferentes dimensões e representantes da sociedade.

O processo de elaboração dos Planos de Educação (Nacional, Estadual, Distrital e Municipal) deve ser articulado com os diversos segmentos da sociedade, uma vez que para atender as demandas e as necessidades da comunidade precisa estar atento para as problemáticas que as circundam no cotidiano. Por isso, a elaboração de um plano implica em "efetiva interação entre os sujeitos, isto é, em abertura de um diálogo que permita a manifestação das opiniões de todos quantos são convidados a se engajar no processo de sua construção" (SOUZA, 2010, p. 20).

Em relação ao processo de elaboração do PME no Brasil, estudos (ARGOLO, 2014; Silva, 2014) revelam que, em sua grande maioria, os sujeitos participaram da sua elaboração, incluindo os movimentos e entidades sociais, os profissionais da educação, alunos, pais de alunos, enfim, todos os segmentos que compõem a sociedade civil. Isso significa dizer que houve um processo mais aberto, democrático, participativo, o que nos faz perceber uma abertura para as decisões políticas no campo educacional. O envolvimento dos sujeitos nas formulações das políticas públicas pode favorecer um planejamento voltado para as prioridades da comunidade (SOUZA, 2010).

Desse modo, é possível compreender que quanto maior for o envolvimento dos sujeitos na elaboração do planejamento voltado para atender as necessidades da comunidade, mais sentido terá para a educação e, sobretudo, para a escola. Porém, estudos (PAIVA, 2009; AUGUSTO, 2010; MENDES, 2012) também apontam que, em alguns municípios brasileiros, os sujeitos não participaram ativamente da elaboração do PME, o que pode indicar uma centralidade na gestão e nas decisões políticas.

A participação dos cidadãos nos mecanismos de proposições e controle das políticas públicas está assegurada pela Constituição de 1988, quando ressalta no artigo $1^{\circ}$, parágrafo único que "todo o poder emana do povo, que o exerce por meio de representantes eleitos ou diretamente, nos termos desta Constituição". Nessa perspectiva, o objetivo do texto é apresentar as modificações na organização e na gestão da escola por meio da implementação do PME no "chão" da escola pública. 
A pesquisa foi realizada por meio de uma abordagem qualitativa que se caracteriza pelo contato direto que o pesquisador tem com a realidade, ou seja, com o campo a ser pesquisado (LUDKE; ANDRÉ, 1986). Utilizamos também a entrevista como instrumento de coleta de dados, podendo conceituá-la como uma conversação entre duas pessoas, entrevistado e entrevistador, que tem como objetivo ouvir opiniões de pessoas que atuam naquele espaço da pesquisa e que conhece a realidade.

O tipo de entrevista aplicada foi a semiestruturada, pois há uma flexibilidade para que o entrevistado possa discorrer sobre o tema em análise, bem como perceber os gestos e expressões durante a sua realização. Entendemos a entrevista como "forma privilegiada de interação social sujeita à mesma dinâmica das relações existentes na própria sociedade" (Minayo, 2010, p. 65). Utilizamos a Análise de Conteúdo (AC) como uma estratégia metodológica para tratamento dos dados, na perspectiva de Bauer (2010), para analisarmos os dados obtidos.

Os sujeitos da pesquisa foram gestores escolares de escolas públicas dos municípios de Recife e de Olinda. Estamos considerando os diretores, os vices diretores e os coordenadores pedagógicos como membros da equipe de gestão escolar, como denomina Libâneo (2004). Foram entrevistados 7 gestores escolares, sendo 3 em 2 escolas municipais de Recife (escolas 1 e 2), gestora da escola 1 (Rosa $^{\mathrm{G} 1}$ ), gestora da escola 2 (Margarida ${ }^{\mathrm{G} 2}$ ) e a vice gestora da escola 2 $\left(\right.$ Simone $^{\mathrm{V} 2}$ ); e os outros 4 participantes em 2 escolas municipais de Olinda (escolas 3 e 4), gestora da escola 3 (Ágata $\left.{ }^{\mathrm{G} 3}\right)$, gestora da escola $4\left(\right.$ Lúcia $\left.^{\mathrm{G} 4}\right)$, vice gestora da escola 3 (Edna $\left.{ }^{\mathrm{V} 3}\right)$ e o coordenador pedagógico da escola $4\left(\right.$ Vicente $\left.^{\mathrm{C} 4}\right)$.

O texto está dividido em 2 partes que se completam, incluindo a introdução e as considerações finas. Na primeira parte, "O Plano Nacional de Educação (2014-2024) e os Planos Municipais de Educação: referências para a política educacional” apresentamos uma reflexão sobre o processo de discussão para a elaboração dos planos de educação (PNE e PME) evidenciando a importância desse planejamento para a consolidação das políticas educacionais. $\mathrm{Na}$ segunda parte, "Modificações na organização e na gestão da escola" destacamos as modificações nas escolas pesquisadas após a implantação do PME nos referidos municípios da pesquisa. Nas considerações finais, apresentamos uma síntese das principais discussões e os impactos do PME no cotidiano de escolas públicas municipais. 
O Plano Nacional de Educação (2014-2024) e os Planos Municipais de Educação: referências para a política educacional

A elaboração do II PNE foi palco de muitas disputas, embates e tensões, uma vez que a sociedade civil organizada e os diversos movimentos da educação estiveram presentes durante todo o processo de sua elaboração, discussão e aprovação. Sua elaboração foi coordenada pelo Ministério da Educação que contou com as contribuições dos documentos desenvolvidos a partir das conferências de educação realizadas em todo o território nacional.

Dessa forma, é pertinente destacar as entidades educacionais que participaram do processo de elaboração do PNE: Associação Nacional de Pós-Graduação e Pesquisa em Educação (ANPED), Associação Nacional de Política e Administração da Educação (ANPAE), Associação Nacional pela Formação dos Profissionais da Educação (ANFOPE), Campanha Nacional pelo Direito à Educação, Centro de Estudos Educação e Sociedade (CEDES), Conselho Nacional de Educação (CNE), Confederação Nacional dos Trabalhadores em Educação (CNTE), Fórum Nacional de Educação (FNE), entre outros interlocutores.

Contribuindo com a discussão acerca do PNE, Bordignon (2011, p. 62) destaca:

[...] O PNE é situado no contexto do projeto nacional de desenvolvimento com inclusão social, ou seja: faz parte de uma política nacional de construção de uma sociedade mais justa, solidária e inclusiva. Neste sentido, estabelece os patamares educacionais nacionais necessários à construção da sociedade preconizada, traduzidos no direito à educação com qualidade social, ações afirmativas e respeito à diversidade, garantidas por uma organização de sistema nacional, com o Conselho Nacional como órgão normativo e o Fórum Nacional como instância de mobilização e participação.

Sobre este aspecto, Marino (2013, p. 180) acrescenta:

A criação do PNE tem como principal objetivo ordenar o planejamento educacional para que algumas metas sejam alcançadas. Tais metas são estabelecidas a partir de estudos feitos para evidenciar os principais problemas da educação do país. Partindo então da situação atual, o PNE tende a modificála a partir do ordenamento de políticas que já estão previstas dentro do próprio Plano

Diante desse contexto, cabe ao Estado brasileiro levar em consideração o documento do plano a fim de promover as políticas públicas educacionais para os próximos dez anos. Somente assim, o PNE ganha força tornando-se elemento necessário para o planejamento educacional brasileiro.

Em relação ao processo de elaboração do PNE (2014-2024), vale destacar que ele passou a tramitar na Câmara dos Deputados como Projeto de Lei $n^{\circ} 8.035 / 2011$. O PL definia as 
diretrizes e disposições para a realização e avaliação do PNE, a saber: 1) realização de duas conferências nacionais, com intervalo de quatro anos entre elas; 2) criação do Fórum Nacional de Educação; 3) regime de colaboração entre os entes federados; 4) acompanhamento das metas através da adoção de mecanismos locais, estados e municípios; 5) adoção do regime de colaboração específico para a educação escolar indígena; 6) elaboração, no prazo de um ano, de planos decenais dos estados, Distrito Federal e municípios; 7) edição, no prazo de um ano, pelos estados, Distrito Federal e municípios, de leis específicas para a gestão democrática; 8) formulação, pela União, estados, Distrito Federal e municípios, de planos plurianuais e diretrizes orçamentárias, e 9) utilização do IDEB, calculado pelo INEP, para a avaliação da qualidade da educação básica (BORDIGNON, 2011).

O PL n $n^{\circ}$ 8.035/2011 durou aproximadamente 4 (quatro) anos em tramitação, sendo sancionado pela presidenta Dilma Russeff em 25 de junho de 2014 (PNE 2014-2024), contendo 20 metas e 254 estratégias. Segundo Martins (2014, p. 23) a "Lei no 13.005/2014 traz importantes instrumentos para viabilizar as ações conjuntas em regime de colaboração e o monitoramento contínuo do processo de execução do PNE”. Assim, o art. $5^{\circ}$ estabelece:

Art. 5o A execução do PNE e o cumprimento de suas metas serão objeto de monitoramento contínuo e de avaliações periódicas, realizados pelas seguintes instâncias:

I - Ministério da Educação - MEC;

II - Comissão de Educação da Câmara dos Deputados e Comissão de Educação, Cultura e Esporte do Senado Federal;

III - Conselho Nacional de Educação - CNE;

IV - Fórum Nacional de Educação (BRASIL, 2014).

O PNE é um instrumento de planejamento da educação brasileira que permite a sociedade civil organizada participar da sua implantação, bem como possibilita aos órgãos competentes avaliar periodicamente se suas metas estão sendo cumpridas. Para tanto, torna-se necessário pensar o Plano Nacional de Educação, "não como um produto, mas como um processo, que tem distintos níveis de elaboração que estabelecem entre si relações de mútua determinação" (KUENZER, 2001, p. 84).

Dourado (2014, p. 232) destaca que:

O PNE envolveu a mobilização da sociedade civil, da sociedade política e do campo educacional, um campo em disputa de projetos, de concepção de mundo, de homem e de sociedade. E, certamente, um plano decenal para a educação cuja regência é de 2014 a 2024 traz um conjunto de questões. Se entendido como epicentro da política educacional, ele pode propiciar avanços importantes na educação, enfrentando questões centrais como o analfabetismo, a universalização do atendimento escolar, a superação das desigualdades educacionais, a melhoria da qualidade, uma formação mais ampla, humanística, 
científica, cultural e tecnológica, a valorização dos profissionais, o respeito aos direitos humanos, à diversidade, sustentabilidade ambiental e ao princípio da gestão democrática.

Dessa forma, entendemos que o PNE se caracteriza como parte integrante do planejamento educacional brasileiro, permitindo a participação e a mobilização da sociedade civil organizada nas tomadas de decisões para o planejamento da educação brasileira, no qual foram discutidos através de conferências, encontros e seminários as necessidades e perspectivas do país em relação à educação. Na visão de Dourado (2014, p. 233) “o PNE foi um avanço, mas é preciso a participação da sociedade civil e da sociedade política para fazer valer as metas e diretrizes. Para que não se torne letra morta, é imprescindível que ganhe materialidade e seja plenamente executado".

A elaboração dos PMEs foi alvo de discussões, embates, conflitos, contradições e debates em todo o território nacional. Isso porque a Lei de Diretrizes e Bases da Educação Nacional, de 20 de dezembro de 1996, incorporou o princípio da gestão democrática no sistema público de ensino, pressupondo o envolvimento coletivo na gestão dos processos administrativos, pedagógicos e financeiros. Com a aprovação do PNE, em 25 de junho de 2014, este exigiu legalmente que todos os municípios elaborassem ou reformulassem seus planos municipais no prazo de um ano de vigência da referida lei, como está prevista na Lei n. 13.005/2014.

O processo de elaboração dos planos municipais mobilizou diferentes segmentos sociais e educacionais, o que pode ter sido construído de modo coletivo e participativo, uma vez que a CF de 1988 e a LDB de 1996 preconizam o princípio da gestão democrática na organização dos processos de gestão. Para Diniz (2015, p. 1) “os Planos não se constituem tão somente em uma exigência legal, são também uma reivindicação por parte de educadores e da sociedade, como forma de fazer um planejamento educacional em longo prazo". Desse modo, a elaboração dos PMEs favorece a superação das descontinuidades das políticas educacionais.

A concepção de planejamento e sua implementação, bem como a melhoria da qualidade em educação precisam ser consideradas pela União, os estados, os municípios e pelo distrito federal, a fim de que definam as metas e as estratégias para a educação de acordo com as necessidades dos sistemas públicos de ensino. Essa ação só será possível se houver um planejamento articulado e participativo envolvendo todos os segmentos da sociedade.

É importante que a construção do PME possa estar em consonância com os Planos Nacional e Estadual de Educação, verificando as metas e as estratégias de cada plano. De acordo com Argolo (2014, p. 49) o PME deve "impactar, decisivamente, sobre os resultados educacionais em todo o Estado, elevar os indicadores educacionais, e contribuir, diretamente, 
para a organização dos Sistemas Municipais de Ensino e, consequentemente, resultar em uma educação de qualidade". Dessa forma, o PME se constitui como instrumento de elaboração das políticas públicas para a educação municipal. Para Bordignon (2009, p. 92):

O plano municipal de educação é o instrumento de gestão para tornar efetiva a cidadania e a sociedade preconizada nas bases e diretrizes do Sistema Municipal de Educação. Quando o município não tem plano fica à mercê de ações episódicas que, mesmo planejadas caso a caso, representam improvisações. Sem plano não há visão de Estado nas ações, não há caminho a percorrer, mas apenas ao saber das circunstancias de cada Governo.

De acordo com a regulamentação em vigência, o PME deveria ser um documento que estabelece metas e estratégias para serem cumpridas em um prazo de 10 (dez) anos, caracterizando-se como uma política de Estado $^{1}$ e não como uma política de governo ${ }^{2}$. Logo, as ações que forem traçadas para a educação municipal perpassam mais de uma gestão, sempre procurando atender os objetivos e as reais necessidades de cada realidade. Assim, todo município, com a determinação do PNE, deve construir seu plano tornando-o o norte para a definição das políticas públicas educacionais, dimensionando os recursos financeiros para o cumprimento das metas em regime de colaboração com a União e o estado.

Para Monlevade (2002), o PME é o epicentro para a consolidação de um projeto de desenvolvimento em que todos os munícipes precisam ter o conhecimento da situação econômica e social, a fim de contribuírem de forma significativa no processo de elaboração do plano. Assim, o PME não pode ser um planejamento de gabinete, construído a partir da visão do gestor local e seus representantes, mas um plano pautado pelas decisões políticas em que atenda os aspectos políticos, econômicos, sociais, culturais e educacionais da sociedade. A consolidação do PME pelos municípios é uma recomendação da legislação educacional que, por sua vez,

[...] reforça o conceito de democracia participativa, sistematiza as ações, visando a garantia do cumprimento das metas e prazos, garante a continuidade das ações, incorpora inovações consistentes e bem projetadas, otimiza os recursos, promove a participação efetiva dos cidadãos (ARGOLO, 2014, p. 51).

O processo de elaboração do PME constitui-se como um instrumento de transformação nos moldes da democratização, uma vez que surge nas correlações de forças entre o governo e a sociedade civil no intuito de solucionar as necessidades sociais. Assim, faz-se necessário destacar

1 As políticas de Estado são aquelas que envolvem mais de uma agência do Estado, passando em geral pelo Parlamento ou por instâncias diversas de discussão, resultando em mudanças de outras normas ou disposições preexistentes, com incidência em setores mais amplos da sociedade (Oliveira, 2011, p. 329).

${ }^{2}$ Considera-se que políticas de governo são aquelas que o Executivo decide num processo elementar de formulação e implementação de determinadas medidas e programas, visando responder às demandas da agenda política interna, ainda que envolvam escolhas complexas (Oliveira, 2011, p. 329). 
as concepções de Boneti (2007, p. 74) sobre políticas públicas afirmando-as como "resultado da dinâmica do jogo de forças que se estabelece no âmbito das relações de poder, relações essas constituídas pelos grupos econômicos e políticos, classes sociais e demais organizações da sociedade civil".

Corroborando com essa discussão, Gadotti (1993, p. 11) salienta que:

A eficiência do PME só terá resultado na medida em que for elaborado, criado e implementado pelos principais agentes de educação municipal sob a coordenação do Conselho Municipal de Educação, a partir do conhecimento das realidades e necessidades locais. Sendo assim, o PME poderá se firmar e significar uma ferramenta e uma promessa de melhoria da qualidade dos sistemas locais de ensino.

A participação dos sujeitos nas tomadas de decisões, na elaboração, no monitoramento e na avaliação das políticas/planos implica na criação de mecanismos legais do governo a fim de ouvir as discussões, as propostas e os encaminhamentos de um grupo que deseja construir uma sociedade igualitária, justa e inclusiva, por meio da política e do planejamento educacional.

No que se refere à gestão da educação, esta é apresentada na meta 19 (dezenove), desdobrando-se em 8 (oito) estratégias no PNE e no PME de Recife e 18 (dezoito) no PME de Olinda, tendo como concepção a gestão democrática. A gestão democrática da educação é um dos princípios constitucionais garantidos na Constituição Federal de 1988, em seu artigo 206, inciso "VI - gestão democrática do ensino público, na forma da lei"; e na Lei de Diretrizes e Bases da Educação Nacional (LDB - Lei no 9.394/1996), em seu artigo 14, assegurando a participação dos profissionais da educação na elaboração do projeto político-pedagógico das instituições de ensino e a participação da comunidade escolar e local nos conselhos escolares.

A gestão democrática da educação se apresenta como uma possibilidade para a educação nacional em que envolve a participação dos diversos segmentos da escola, pais, professores, estudantes e demais funcionários, na elaboração e implementação dos planos da educação, dos projetos político-pedagógicos das escolas, bem como na organização e efetivação dos sistemas de ensino, entre outros mecanismos. Com a participação destes sujeitos nas políticas educacionais, as condições de melhorias para a escola pública tornam-se viáveis, construindo uma educação de boa qualidade para todos os níveis, modalidades e etapas. Nesse sentido, para a concretização da meta que trata da gestão escolar e suas estratégias "é fundamental aprimorar as formas de participação e de efetivação dos processos de autonomia pedagógica, administrativa e de gestão financeira, bem como os processos de prestação de contas e controle social" (RECIFE, 2015, p. 184). 
Modificações na organização e na gestão da escola: as vozes dos participantes

Delgado (2012, p. 3) afirma que as políticas públicas interferem e apresentam modificações "no interior da escola, em especial, nos seus princípios e, por decorrência, na forma de organização e desenvolvimento do trabalho escolar, portanto, interferindo diretamente nas práticas dos professores e em sua cultura". Assim, toda política pública tem como intenção interver em uma determinada realidade propondo-se a contribuir para a melhoria da situação vivenciada pela população local. Desse modo, buscamos apreender as possíveis alterações ocorridas no cotidiano das escolas pesquisadas no que diz respeito a sua organização e gestão por meio do PME, através da visão de gestores escolares.

Ao perguntarmos aos gestores de Recife se houve modificações na organização e na gestão da escola após a implantação do PME, dentre as respostas predominantes se destacaram as negativas como a que exemplificamos abaixo:

Não. Porque todo esse tempo que tou aqui, que estou à frente dessa escola, a gente tem trabalhado em cima do que já vinha em termos de verbas, de projetos. A gente vem trabalhando sempre o que já recebia e o que a gente faz aqui é mais interno quando vêm sugestões dos professores (Margarida ${ }^{\mathrm{G} 2}$ ).

Por meio do depoimento, é possível perceber que não houve nenhuma modificação com a implantação do PME e que as atividades realizadas na instituição decorrem dos projetos e das verbas que já vinham para a escola e que todo o trabalho desenvolvido é a partir das sugestões dos docentes. De acordo com a fala da gestora, podemos compreender que o PME não contribuiu de forma significativa nas ações das escolas pesquisadas. Simone ${ }^{\mathrm{V} 2}$, vice gestora de Recife, destacou que "bouve mais formações”. No entanto, mesmo as metas 15, 16, 17 e 18 do PNE 2014-2024 e do PME de Recife tratarem desse cenário de formação dos professores, esse aspecto já tem sido garantido pelo Fundo de Manutenção e Desenvolvimento da Educação Básica e de Valorização dos Profissionais da Educação (FUNDEB).

Sobre a formação dos professores na realidade de Recife, por meio da repercussão do PME, foi possível perceber:

Os professores participam da formação na secretaria. Agora, de forma alguma essa formação está contenta, péssima, péssima, de péssima qualidade [...] A secretaria inventou uma política de ensino [...] E eles pensaram a política de formação toda em cima dessa política de ensino [...] Voltou acho que 30, 40 anos. Lembra daquela época que dizia assim: dependendo do que eu ensino, o menino aprende? E voltou isso. Não chega na ponta, não chega na escola. A questão de formação continuada não dar conta em nenhuma área de conhecimento (Rosa ${ }^{\mathrm{G} 1}$ ) (grifo nosso). 
Como vimos, a formação dos professores é um mecanismo necessário na efetivação de práticas pedagógicas, porém, ao discutirmos a relevância desse instrumento para a elaboração de políticas públicas precisamos destacar também como está sendo ofertada essa formação, quem são os responsáveis por ela, quais os entraves e os desafios que perpassam no ambiente escolar, isso porque espera-se que a formação profissional desenvolva ações que tenham como objetivo melhorar a qualidade da educação.

De acordo com os resultados obtidos, a partir dos depoimentos, a formação proposta pela secretaria não é de boa qualidade, pois não condiz com a realidade da escola. Segundo Rosa $^{\mathrm{G} 1}$, a política de formação do município de Recife está em consonância com a política de ensino, elaborada no intuito de nortear todo o trabalho pedagógico, de acordo com a organização curricular. Porém, na visão da gestora, a política de ensino está ultrapassada, não aborda questões atuais que envolvem a realidade dos estudantes e dos professores.

De um modo geral, os dados apontam que houve um retrocesso em relação à formação dos professores, pois não atende as expectativas e as demandas apresentadas pelas escolas, uma vez que seria importante acompanhar as mudanças sociais que vem ocorrendo no cenário educacional. Desse modo, a formação de professores está atrelada à concepção de educação, de homem e de sociedade que queremos formar, como aponta Vieira (2012, p. 19) "se queremos entender o sentido das reformas educacionais em curso, precisamos dirigir o olhar para essas reformas globais que as motivam e imprimem contornos a seus rumos". Logo, a política de formação dos professores é uma questão relevante, tendo em vista que as temáticas e discussões norteiam o trabalho pedagógico e político das instituições educativas.

A qualidade da educação perpassa, entre outros aspectos, pela formação dos professores, uma vez que a qualificação contribui de forma significativa no processo de ensino e de aprendizagem, tendo em vista as mudanças ocorridas no cenário brasileiro a partir da década de 1990, por meio da Reforma do Estado, a qual previa a inserção de avaliações em larga escala para dimensionar a qualidade da educação, situação que se concretizou e se agravou nos dias atuais. Assim, levar em consideração a formação dos professores requer um planejamento voltado para as necessidades do docente, do educando e da escola pública, em geral. Nesse contexto, Vieira (2012) apresenta os tipos de formação como mecanismos importantes para o desenvolvimento profissional, a saber: formação inicial, formação continuada, formação em serviço, treinamento e capacitação.

Já os gestores de Olinda destacaram algumas modificações no cotidiano escolar advindas do PME, como: 
A rede física que tá sendo feita. A formação que eu acho muito importante e quando ele fala na questão do princípio da gestão democrática que é uma das diretrizes e vai nortear esse nosso processo de eleição (ÁgataG3) (Grifos nossos).

Tá. Não vou dizer na íntegra, mas em alguns pontos está sim. A formação é feita por lá (secretaria). A questão da valorização [...] Tem a formação também para os $5^{\circ}$ s e $9^{\circ}$ s anos, mandaram as provas e eles vão fazer quatro simulados. Então a parte de monitoramento e de dar condições pra que tenha uma melhoria [...] (Edna $\left.{ }^{\mathrm{V} 3}\right)$ (Grifo nosso).

Pouco. Nós temos agora a formação continuada do $5^{\circ}$ ano e do $3^{\circ}$ ano, na verdade, do $1^{\circ}$ ao $3^{\circ}$ ano, a gente precisa pensar que o discurso que está posto no plano municipal, a estrutura organizacional de ensino precisa também ser repensada. O currículo precisa ser repensado (LúciaG4) (Grifo nosso).

A gente teve uma modificação na escolha da gestão. A gente já teve dias tenebrosos aqui de indicação. Hoje a gente tem uma eleição bem democrática pra gestor. Antes era muito da coisa da indicação política, era extremamente problemática, a gente sabe disso, mas a gente teve momentos muito difíceis e com o plano municipal as tensões foram sendo diminuídas, agora, não tudo. A educação infantil tá ganhando uma identidade, tem um grupo que tá a frente, mostrando a importância da educação infantil, mas a educação infantil passou um período depois do plano sufocada [...]. A gente tem formação específica para o professor do $5^{\circ}$ ano, do $3^{\circ}$ ano, o município abraçou o PNAIC. Então isso tudo foi algo que foi pedido no plano e que tá sendo aos poucos implementado (Vicente ${ }^{\mathrm{C}}$ ) (Grifos nossos).

Os gestores de Olinda destacaram aspectos positivos em relação ao PME, pois se percebeu modificações no cotidiano escolar após a sua implantação, isso porque o planejamento está sendo colocado em prática, mesmo que timidamente. É relevante mencionar que a concretização do plano como política pública depende do grupo político que está direcionando as ações, isso repercute diretamente no contexto da escola. Cabe destacar, ainda, que o Pacto Nacional pela Alfabetização na Idade Certa (PNAIC) é uma política de formação para professores que foi desenvolvida pelo governo federal antes do processo de elaboração do PME, não estando, portanto, diretamente ligado a ele. O PNE já apresenta a formação continuada dos profissionais da educação para o desenvolvimento de atividades com as crianças de 6 a 8 anos de idade que correspondem do $1^{\circ}$ ao $3^{\circ}$ ano do ensino fundamental, como podemos observar na meta 5 do respectivo plano: "alfabetizar todas as crianças, no máximo, até o final do $3^{\circ}$ (terceiro) ano do ensino fundamental".

De acordo com os depoimentos, as melhorias desenvolvidas na educação de Olinda referem-se à infraestrutura da escola, uma vez que esta passou por uma reforma para atender, principalmente, os alunos com necessidades especiais, tendo em vista que a escola atende um número significativo de alunos que demandam uma estrutura física especial. Nas reformas foram construídas rampas, banheiros adaptados e fornecido materiais didáticos adequados para o desenvolvimento das atividades. 
A educação infantil também foi contemplada na reforma, um espaço amplo e aberto foi construído para que as crianças pudessem ter um ambiente no qual desenvolvessem suas atividades, brincadeiras, e os banheiros que já existiam dentro das salas de aula foram reformados, deixando-os adaptados para o tamanho das crianças. Em relação às reformas, o PME de Olinda sinaliza na estratégia 1.8: "garantir a reforma e manutenção dos espaços educacionais que já ofertam educação infantil". Mas essas ações podem não ter sidas realizadas por meio das políticas postas no PME, mas dos recursos do FUNDEB que prevê reformas nas escolas da educação básica.

O estudo de Neto (et. al., 2013) demonstra que a infraestrutura dos prédios escolares contribui significativamente no aprendizado dos alunos. Desse modo, salientamos a importância de políticas públicas que visem à diminuição de escolas que não possuem uma infraestrutura adequada para atender os alunos, promovendo um padrão mínimo de condições escolares para que ocorra uma aprendizagem em um espaço propício para esse fim. Mais uma vez, cabe destacar que essas reflexões foram acordadas no processo de implantação do FUNDEB, o qual pode realizar reformas e novas construções de escolas.

Outro aspecto apresentado pelos gestores é a formação dos professores que vem ocorrendo no município de Olinda depois da implantação do PME. No entanto, destacamos que essa questão não surgiu com a aprovação do Plano, mas com o FUNDEB. Os depoimentos sinalizaram a formação como mecanismo necessário para a melhoria da aprendizagem dos alunos, uma vez que a Secretaria Municipal de Educação (SEMED) de Olinda utiliza-se de provas e simulados para acompanhar o rendimento dos estudantes, como aponta Edna ${ }^{\mathrm{V} 3}$. Destacamos, porém, que a formação dos professores na perspectiva das reformas educacionais em que se enfatiza a produtividade, a eficiência, a eficácia e a avaliação por resultados não se configura como uma formação para a prática da transformação, da emancipação e da igualdade de oportunidades.

Dessa forma, é necessário comentar que o PNE na meta 7 apresenta os resultados do Índice de Desenvolvimento da Educação Básica (IDEB) como diagnóstico para quantificar a qualidade da educação: "fomentar a qualidade da educação básica em todas as etapas e modalidades, com melhoria do fluxo escolar e da aprendizagem de modo a atingir as médias nacionais para o Ideb”. Essa lógica está fundamentada nos ditames da política neoliberal, a qual tem como princípio os padrões do mercado, salientando essas ações no contexto da política da educação e no interior das escolas. 
A eleição de gestores como princípio da gestão democrática foi outro aspecto destacado pelos gestores de Olinda. Cabe salientar que esse mecanismo da gestão democrática já existia no município, porém, com o PNE e o PME como uma política educacional passou a ser mais evidenciado. Os gestores apontaram a eleição como um mecanismo necessário presente no PME na meta 19: "assegurar condições, no prazo de 2 (dois) anos, para a efetivação da gestão democrática da educação [...]”, bem como na estratégia 19.1: “criar um projeto de lei que garanta o provimento do Cargo de diretores (as) e vice-diretores (as) de escola", e que está sendo vivenciado com mais vigor nas escolas do município. Para eles, foi uma conquista importante para a educação, pois antes a indicação política prevalecia na forma de escolher os gestores para atuarem nas escolas. Assim, a eleição de diretor busca romper com o paradigma de práticas autoritárias e clientelistas que não contribuem para o processo democrático.

Segundo Vicente ${ }^{\mathrm{C}}$, a educação infantil está ganhando uma nova identidade, ou seja, com a gestão atual e a implantação do PME, essa etapa da educação básica passou a ter mais visibilidade no campo educacional, pois existe um grupo responsável para discutir ações que possam contemplar as necessidades das crianças e lutar por melhorias para essa etapa escolar. Esse é um aspecto interessante porque após a aprovação da CF/1988, o Estatuto da Criança e do Adolescente/1990 (ECA) e a LDB/1996 a educação infantil vem ganhando destaque nas políticas públicas, afirmando a necessidade de ampliação de vagas e a valorização dessa etapa, mesmo que timidamente.

Após a aprovação da Emenda Constitucional no 59 de 2009, a pré-escola, segunda etapa da educação infantil, passou a ser obrigatória, sendo necessária a efetivação de políticas para essa ação. Os avanços para a educação infantil surgiram nessa perspectiva, o PME reforça essa proposição, contribuindo para as melhorias na oferta da primeira etapa da educação básica. Nesse sentido, "considerar a educação infantil como primeira etapa da educação básica representou um avanço para a educação pública brasileira” (BARBOSA, et. al., 2014, p. 505).

Conforme apresentado, as mudanças destacadas nos depoimentos sinalizaram que os avanços educacionais foram concretizados por meio de políticas já existentes no âmbito do planejamento educacional. Ao que se refere ao PME, cabe destacar que falta o monitoramento para as metas e as estratégias que foram planejadas. Desse modo, o policiamento dos órgãos competentes para a implementação do plano e a participação da sociedade civil para cobrar a efetivação das metas do PME são relevantes, objetivando melhorar cada vez mais a educação pública brasileira. 


\section{Considerações finais}

As proposições sinalizadas ao longo do texto possibilitaram compreender que as políticas educacionais referentes ao planejamento educacional e a gestão escolar consolidam ações que marcam o caráter coletivo no processo de vivência das práticas educativas. A gestão escolar democrática e os seus mecanismos contribuem para que diferentes segmentos possam estar inseridos nas decisões, como preconizam as normatizações.

É válido, também, apresentar que a consolidação das políticas públicas apresenta resistências e se caracteriza como um processo de idas e vindas, dependendo da concepção política do grupo que está a frente da política local, consolidando assim, um processo de rupturas e permanências. A política educacional é fruto dos dilemas vivenciados no âmbito da construção de uma determinada ação, sendo necessária a participação dos movimentos social e político para caracterizar o confronto de interesses.

A concretização do PNE e dos diferentes PMEs no contexto brasileiro é vista como um avanço político, social e educacional, pois sinaliza um anseio coletivo, a partir da escuta de diferentes vozes, causando impactos no "chão" da escola e na organização da política educacional. No entanto, é necessário destacar que a conjuntura política pode desfavorecer esse princípio, uma vez que novos grupos estão a frente da estrutura política brasileira, sendo contrários aos avanços educacionais que estavam em curso.

No que se refere ao objetivo do texto, apresentar as modificações na organização e na gestão da escola por meio da implementação do PME no "chão" da escola pública, foi possível perceber que as proposições evidenciadas possibilitam refletir que, diretamente, os Planos de Recife e de Olinda não causaram modificações no modo de organização na gestão da escola. As questões destacadas, especialmente formação de profissionais e melhorias nas estruturas dos prédios, são aspectos que já eram direcionados por meio do FUNDEB. Podemos afirmar que as políticas sinalizadas pelos participantes são conquistas de lutas anteriores ao PNE e ao PME.

A consolidação de políticas educacionais necessita da participação ativa dos diferentes segmentos para monitorar as estratégias planejadas e cobrar dos governantes ações concretas para a viabilização de melhorias no cenário da educação brasileira. É preciso atuar com resistência e fazer valer as políticas de Estado, como o PNE e o PME, a fim de que as conquistas cheguem ao "chão" da escola e consolidem possibilidades de avanços sociais, educacionais e políticos.

De um modo geral, pode-se perceber que a construção da política é um campo de disputas e essas são configuradas por grupos que têm interesses social, econômico, religioso, político, educacional conduzindo as proposições planejadas com a finalidade de alcançar os seus 
objetivos. Desse modo, os embates políticos são resultados de interesses que, na maioria das vezes, causam impactos na condução dos projetos sociais.

A política educacional, nessa perspectiva, é um campo que pode construir os projetos em pauta e evidenciar princípios e ações para serem vivenciados pela sociedade, respondendo, assim, a um projeto maior. Por fim, evidencia-se que a construção de um projeto de sociedade é resultado de grupos que planejam uma determinada concepção de homem, de mundo, de educação, de ser humano. O protagonismo de cada pessoa é importante para romper com modelos construídos por forças hegemônicas e viabilizar novas possibilidades de educação, cujo compromisso seja em uma perspectiva plural, democrática e inclusiva...

\section{Referências}

ARGOLO, Fernanda Karla de Santa Reis. O processo de elaboração do Plano Municipal de Educação de Santo Antônio de Jesus-BA (2005-2014): uma análise sobre a participação dos sujeitos. Dissertação (Mestrado em Educação e Contemporaneidade). Universidade do Estado da Bahia, Santo Antônio de Jesus/BA, 2014.

AUGUSTO, Bruno Brandão. Gestão dos sistemas de ensino: análise das relações democráticas na construção do Plano Municipal de Educação de Volta Redonda. Dissertação (Mestrado em Educação). Universidade do Estado do Rio de Janeiro, Duque de Caxias/RJ, 2010.

BARBOSA, Ivone Garcia; ALVES, Nancy Nonato de Lima; SILVEIRA, Telma Aparecida Teles Martins; SOARES, Marcos Antônio. A educação infantil no PNE: novo plano para antigas necessidades. Revista Retratos da Escola, Brasília, vol. 8, n. 15, 2014.

BAUER, Martin W. Análise de conteúdo clássica: uma revisão. In: BAUER, Martin W.; GASKELL, George (Orgs.). Pesquisa qualitativa com texto, imagem e som: um manual prático. Petrópolis, RJ: Vozes, 2010.

BONETI, Lindomar Wessler. Políticas públicas por dentro. Ijuí: Unijuí, 2007.

BORDIGNON, Genuíno. Gestão da Educação no Município: sistema, conselho e plano. São Paulo: Instituto Paulo Freire, 2009.

BORDIGNON, Genuíno. O planejamento educacional no Brasil. Brasília, 2011.

BRASIL. Constituição da República Federativa do Brasil. Brasília, 1988.

BRASIL. Lei no. 9.394, de 20 de dezembro de 1996. Lei de Diretrižes e Bases da Educação Nacional. Estabelece as Diretrizes e Bases da Educação Nacional.

BRASIL. Presidência da República. Lei n 13.005. Aprova o Plano Nacional de Educação e dá outras providências. Brasília, 25 de junho de 2014. 
BRASIL. Projeto de Lei do Plano Nacional de Educação (PNE 2011/2020): projeto em tramitação no Congresso Nacional / PL no 8.035 / 2010. Brasília: Câmara dos Deputados, Edições Câmara, 2011.

DELGADO, Adriana Patrício. O impacto das políticas públicas nas práticas escolares sob a ótica da avaliação de aprendizagem. Espaço do Currículo, v. 4, n. 2, p.162-171, Setembro de 2011 a Março de 2012.

DINIZ, Adriana Valéria Santos. A construção dos novos planos estaduais e municipais de educaşão: fundamentos, desafios e perspectivas. Disponível em:

<http://www.anpae.org.br/simposio2015/\#/gt4-com> Acesso em 14 de out. de 2016.

DOURADO, Luiz Fernandes. Plano Nacional de Educação, Conferência Nacional de Educação e a construção do Sistema Nacional de Educação: dilemas e proposições. Revista Jornal de Políticas Educacionais, no 16, p. 03-11, jul./dez. 2014.

GADOTTT, Moacir. Município e educação. São Paulo: Cortez, 1993.

HORTA, José Silvério Baía. Liberalismo, Tecnocracia e planejamento educacional no Brasil: uma contribuição à história da educação brasileira no período 1930-1970. São Paulo: Cortez: Autores Associados, 1982.

KUENZER, Acácia Zeneida. Política educacional e planejamento no Brasil: os descaminhos da transição. In: KUENZER, A.; CALAZANS, M. J. C.; GARCIA, W. (Orgs.). Planejamento e educação no Brasil. São Paulo: Cortez, 2001.

LIBÂNEO, José Carlos. Organização e gestão da escola: teoria e prática. Goiânia: Editora Alternativa, 2004.

LUDKE, Menga; ANDRÉ, Marli. Pesquisa em Educação: Abordagens qualitativas. São Paulo: E.P.U. 1986.

MARINO, Diego Jasmin. O planejamento da educação básica no contexto do novo Plano Nacional de Educação 2011-2020. Dissertação (Mestrado em Educação). Universidade do Estado do Rio de Janeiro, São Gonçalo/RJ, 2013.

MARTINS, Paulo Sena. A bistória do PNE e os desafios da nova lei. Brasília: Consultoria Legislativa da Câmara dos Deputados, 2014.

MENDES, Maria de Fátima. Plano Municipal de Educação: implementação e participação social. Dissertação (Mestrado em Educação). Universidade Federal de Juiz de Fora, Juiz de Fora/MG, 2012.

MINAYO, Maria Cecília de Souza (org.). Pesquisa Social: teoria, método e criatividade. 29 ed. Petrópolis, RJ: Vozes, 2010.

MONLEVADE, João A. Plano Municipal de Educação: fazer para acontecer. Ideia, Brasília, 2002.

NETO, Joaquim José Soares; JESUS, Girlene Ribeiro de; KARINO, Camila Akemi; 
ANDRADE, Dalton Francisco de. Uma escala para medir a infraestrutura escolar. Estudos de Avaliação Educacional, São Paulo, v. 24, n. 54, p. 78-99, jan./abr. 2013.

OLINDA. Lei $n^{\circ}$ 5940/2015. Dispõe sobre a adequação do Plano Municipal de Educação de Olinda, conforme disposição do art. $8^{\circ}$ da Lei n 13.005/201, que aprova o Plano Nacional de Educação- PNE e dá outras providências.

OLIVEIRA, Dalila Andrade. Das políticas de governo à política de Estado: reflexões sobre a atual agenda educacional brasileira. Educaşão \& Sociedade, Campinas, v. 32, n. 115, p. 323-337, abr./jun. 2011.

PAIVA, Josiane de Souza. Plano Decenal Municipal de Educação: uma análise sobre a participação da sociedade civil no processo de elaboração. Dissertação (Mestrado em Educação). Universidade Federal de Juiz de Fora, Juiz de Fora/MG, 2009.

PERNAMBUCO. Plano Municipal de Educação Lei nº 18.147/2015. Recife, 2015.

SANCHES, Osvaldo M. A participação do Poder Legislativo na análise e aprovação do orçamento. Revista de Informação Legislativa. Brasília, ano 33, n. 131, jul./ set. 1996. p. 59-77.

SAVIANI, Dermeval. Da nova LDB ao novo plano nacional de educação: por uma outra política educacional. Campinas, SP: Autores Associados, 1999.

SOUZA, Eveline Pasqualin. O desafio da construção democrática e participativa de um Plano Municipal de Educação. Dissertação (Mestrado em Educação das Ciências). Universidade Regional do Noroeste do Estado do Rio Grande do Sul, Ijuí, 2010.

VIEIRA, Sofia Lerche. Políticas de formação em cenários de reforma. In: VEIGA, Ilma Passos; AMARAL, Ana Lúcia. (Org.). Formação de professores: políticas e debates. Campinas: Papirus, p. 1344, 2012.

Recebido em: 29 jul. 2019 / Aprovado em: 27 nov. 2019

Cite como (ABNT NBR 6023:2018)

SILVA, Alex Vieira da; SANTOS, Inalda Maria dos. O Plano Municipal de Educação e suas repercussões na escola pública. Dialogia, São Paulo, n. 34, p. 277-294 jan./abr. 2020. Disponível em: https://doi.org/10.5585/Dialogia.N34.14515. 